Marins, R.S.Q.S. Risco de infecção cruzada: transmissão interespécies do papilomavírus humano e animal conferido pela expressão clínica da doença. PUBVET, Londrina, V. 2, N. 48, Art\#463, Dez1, 2008.

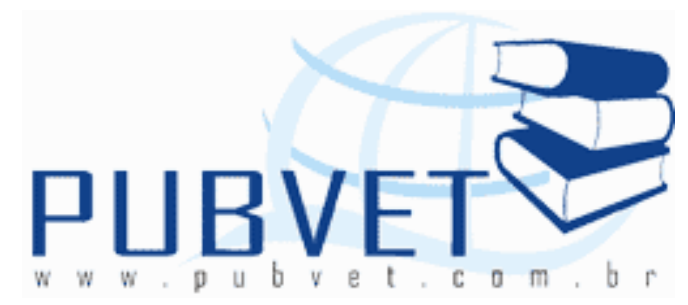

PUBVET, Publicações em Medicina Veterinária e Zootecnia.

https://doi.org/10.31533/pubvet.v02n12a463.1-10

\title{
Risco de infecção cruzada: transmissão interespécies do papilomavírus humano e animal conferido pela expressão clínica da doença
}

\footnotetext{
Rachel Siqueira de Queiroz Simões Marins*

* Médica Veterinária, Mestre em Produção Animal, Doutora em Ciência Animal, UENF.
}

\section{Resumo}

O papilomavírus (PV) pode infectar um amplo espectro de hospedeiros na natureza, dentre eles encontram-se: o homem, animais domésticos, animais de laboratório e espécies silvestres. Este artigo alerta para o risco de infecção cruzada interespécies e transmissão dos tipos virais bovinos para o homem pelo contato direto dos trabalhadores rurais e retireiros no manuseio do úbere e tetas de animais infectados pelo vírus do papiloma durante o ato da ordenha. Igualmente, sinaliza para técnicos de laboratório e pesquisadores o risco em manipular material de vírus vivo. Nesse artigo, será dada maior ênfase ao estudo do papilomavírus humano (Human papillomavirus - HPV) e sua correlação com o papilomavírus bovino (Bovine papillomavirus - BPV) frente à possibilidade do DNA vírus ser transmitido a outras espécies.

Palavras-chave: infecção cruzada, transmissão interespécies, papilomavírus. 
Marins, R.S.Q.S. Risco de infecção cruzada: transmissão interespécies do papilomavírus humano e animal conferido pela expressão clínica da doença. PUBVET, Londrina, V. 2, N. 48, Art\#463, Dez1, 2008.

\section{Introdução}

Baseado em suas propriedades biológicas, o papilomavírus (PV) pode infectar um amplo espectro de hospedeiros na natureza. Segundo o Comitê Internacional de Taxionomia Viral (International Committee on Taxonomy of Viruses - ICTV), os hospedeiros naturais da família Papillomaviridae pertencem ao Domínio Eucarya, Reino Animalia, Filo Chordata e Subfilo Vertebrata. Entre os hospedeiros conhecidos do PV encontram-se a Classe Mammalia, Ordem Primates, Família Hominidae, espécie Homo sapiens (homem). E entre as espécies de animais domésticos encontram-se: bovinos, caninos, caprinos, eqüinos, felinos, ovinos, suínos, animais de laboratório, entre outros (ICTV, 2008).

Em espécies silvestres, as pesquisas ainda são recentes. Novos e diferentes tipos de PVs têm sido identificados por meio de técnicas de clonagem e seqüenciamento, e encontram-se disponíveis no banco de dados (Gen Bank) do Centro Nacional de Informação de Biotecnologia (National Center for Biotechnology Information - NCBI). Algumas destas espécies de PVs em animais silvestres já estão classificadas filogeneticamente entre os 16 gêneros da família Papillomaviridae e outras, ainda não estão devidamente classificadas.

\section{Animais silvestres}

São escassos os estudos epidemiológicos sobre a papilomatose em hospedeiros silvestres. Atualmente as pesquisas buscam a caracterização genômica de variadas espécies silvestres e exóticas, como em golfinhos (Tursiops truncatus) (Rehtanz et al., 2006), koala (Antonsson \& Mc Millan, 2006), leões asiáticos (Panthera leo persica) (Sundberg et al., 1996), morcego (Rousettus aegyptiacus) (Rector et al., 2006), peixe-boi (Trichechus manatus latirostris) (Rector et al., 2004., Woodruff et al., 2005), porco-espinho (Erethizon dorsatum) (Rector et al., 2005b), raposa (Procyon lotor) (Rector et 
Marins, R.S.Q.S. Risco de infecção cruzada: transmissão interespécies do papilomavírus humano e animal conferido pela expressão clínica da doença. PUBVET, Londrina, V. 2, N. 48, Art\#463, Dez1, 2008.

al., 2005a), urso polar (Ursus maritimus) (Stevens et al., 2008), entre outros hospedeiros.

Nesse artigo, será dada maior ênfase ao estudo do papilomavírus humano (Human papillomavirus - HPV) e sua correlação com o papilomavírus bovino (Bovine papillomavirus - BPV) frente à possibilidade do vírus ser transmitido a outras espécies. Até o momento já foram identificados mais de 100 tipos de HPV e novas cepas virais de BPV têm sido detectadas.

\section{Transmissão interespécies: bovino, eqüino e felino}

O BPV é classificado de acordo com o tropismo tecidual e quanto ao caráter histológico das lesões em três grupos, a saber: grupo I (BPV-3 e BPV6) induz uma neoplasia cutânea; grupo II (BPV-4) induz uma hiperplasia do epitélio escamoso não estratificado; grupo III (BPV-1, BPV-2 e BPV-5) induz um fibropapiloma cutâneo (Murphy et al., 1999).

Atualmente, o BPV é considerado o agente etiológico mais provável do sarcóide eqüino, que representa o tumor de pele mais comum nesta espécie. A aplicação de técnicas de biologia molecular como os estudos de hibridização e de reação em cadeia da polimerase (PCR) têm demonstrado que os tumores nos eqüinos contêm seqüências de DNA homólogas às do BPV-1 e BPV-2, caracterizando a transmissão interespécies (Chambers et al., 2003., Nasir et al., 2007).

Histologicamente, tumores cutâneos felinos são diagnosticados na dermatopatologia como sarcóide felino, similares as lesões encontradas nos eqüinos. Recentemente, tem sido demonstrado que o DNA obtido de sarcóides felinos apresenta seqüências de nucleotídeos homólogos aos do BPV-1 e BPV2, evidenciando sinais de uma possível infecção cruzada, como também detectada no sarcóide eqüino (Teifke et al., 2003). 
Marins, R.S.Q.S. Risco de infecção cruzada: transmissão interespécies do papilomavírus humano e animal conferido pela expressão clínica da doença. PUBVET, Londrina, V. 2, N. 48, Art\#463, Dez1, 2008.

De modo geral, as lesões induzidas pelo vírus caracterizam-se como neoformações benignas, de natureza fibroepitelial, usualmente denominadas de papilomas, verrugas e condilomas presentes no tecido epitelial, na mucosa oral e na mucosa anogenital exibindo achados clínicos, morfológicos e microscópicos típicos da virose neoplásica. Podem apresentar sinais de malignização quando há interação entre o vírus e co-fatores ambientais, tais como: a ação de substâncias carcinogênicas da samambaia do campo (Pteridium aquilinum), radiação solar, hábitos alimentares, entre outros fatores envolvidos, que podem ativar o mecanismo de oncogênese e representar um passo essencial para o desenvolvimento do câncer.

\section{Transmissão entre BPV e HPV}

A transmissão interespécies parece ocorrer raramente em casos de DNA vírus, que têm sido propostos como estritamente relacionados às interações moleculares entre vírus e proteínas reguladoras do hospedeiro. Esta restrição não ocorre em todas as papilomaviroses, porque alguns PVs de animais ungulados podem amplificar seqüências do DNA viral em seus hospedeiros heterólogos sob condições naturais e experimentais extremas (Chan et al., 1997).

Contudo, não há registro de nenhum tipo de HPV detectado em animais ou de algum tipo de PV animal detectado em humanos segundo relatos de Chan et al., (1997). Também não há registros de que o BPV possa contaminar o homem, segundo estudos realizados. Entretanto, na década de 40 um pesquisador admitiu ter se contaminado com o BPV ao trabalhar com bovinos infectados pelo vírus. Em um estudo experimental, o BPV foi inoculado em três pacientes humanos, e após três anos somente um deles manifestou sinais clínicos da virose (Mayr e Guerreiro, 1988). 
Marins, R.S.Q.S. Risco de infecção cruzada: transmissão interespécies do papilomavírus humano e animal conferido pela expressão clínica da doença. PUBVET, Londrina, V. 2, N. 48, Art\#463, Dez1, 2008.

Em um estudo molecular, seqüências de DNA de BPV foram detectadas em amostras ovarianas, uterinas, células cumulus, fluidos e oócitos, oriundos de bovinos abatidos não afetados pela papilomatose cutânea, como também em amostras de sêmen usadas em programas de inseminação artificial (Carvalho et al., 2003). Seqüências do DNA viral também foram detectadas por hibridização in situ nos tecidos do trato reprodutivo e nos gametas, mostrando que a infecção não é específica de tecidos epiteliais (Yaguiu et al., 2006). Esses achados alertam para a possibilidade de transmissão do BPV através dos procedimentos de transferência de embriões, inseminação artificial e de fertilização in vitro (Carvalho et al., 2003).

Apesar da transmissibilidade interespécies não ter sido sistematicamente estudada em condições experimentais, não se deve subestimar a falta de registros de casos, dada à proximidade e freqüência do contato dos humanos com os animais domésticos e silvestres (Chan et al., 1997).

\section{Expressão clínica da doença}

Nesse sentido, o presente trabalho relata a ocorrência de lesões epiteliais em humanos que tiveram contato com bovinos portadores de papilomatose cutânea. Foram avaliados clinicamente e registrados diversos casos de lesões verrucosas nas mãos de ordenhadores e trabalhadores rurais em propriedades da região Norte e Noroeste Fluminense e Sul do Espírito Santo. Nestas propriedades, foram observadas nas tetas e úberes de bovinos leiteiros, lesões papiliformes morfologicamente circulares, sésseis e rosadas, ora apresentando maior protuberância similar a neoformações típicas de grão-de-arroz, ora achatadas e multifocais. Também foram encontrados casos de papilomas disseminados pelo corpo acometendo um ou mais animais de um mesmo rebanho apresentando saliências sólidas na forma plana e outras vezes na forma pedunculada similar ao aspecto de couve-flor. 
Marins, R.S.Q.S. Risco de infecção cruzada: transmissão interespécies do papilomavírus humano e animal conferido pela expressão clínica da doença. PUBVET, Londrina, V. 2, N. 48, Art\#463, Dez1, 2008.

Em humanos, foram detectadas lesões semelhantes nas mãos dos ordenhadores que estavam diretamente em contato com bovinos positivos clinicamente para o BPV. Em razão de novos episódios da virose, que têm sido relatados por proprietários e médicos veterinários da região, sugere-se que pode estar havendo uma correlação entre as cepas virais e risco de infeç̧ão cruzada interespécies. Acredita-se que pela forma mamária, a papilomatose bovina possa ser transmitida pelas mãos dos ordenhadores ou por equipamentos de ordenha contaminados pelo contato com lesões durante o manuseio do úbere. Dessa forma, O BPV pode ser carreado até as áreas de abrasões caracterizando um problema de Saúde Pública (Rebhun, 2000).

De acordo com Murphy et al., (1999), suspeitou-se da transmissão da verruga dos bovinos para o homem, devido à alta incidência de verrugas cutâneas nos açougueiros. Embora, o vírus isolado desses funcionários não apresentasse relação com qualquer vírus bovino conhecido daquela época. Antigamente existiam apenas seis cepas virais infectando os bovinos e hoje novas pesquisas já detectaram 11 novos prováveis tipos de BPV (Ogawa et al., 2004).

Também deve-se levar em consideração o manejo sanitário nas propriedades. Algumas apresentavam bovinos com um grande número de carrapatos e moscas, podendo veicular o vírus. Segundo relatos dos trabalhadores rurais, os carrapatos caem e no local surge uma pequena verruga, que na maioria dos casos aumenta e tende a se proliferar em diversas regiões corpóreas de acordo com o estado imunológico de cada animal. Tal hipótese foi sugerida por Barrat em 1925 ao responsabilizar, embora com pequena evidência, as moscas como vetores mecânicos na transmissão da papilomatose. A possibilidade de contato com insetos (Stomoxys calcitrans e Aedes aegypti) ou a proximidade de roedores não pode ser completamente descartada (Wittmann, 1999; Miller et al., 2003). 
Marins, R.S.Q.S. Risco de infecção cruzada: transmissão interespécies do papilomavírus humano e animal conferido pela expressão clínica da doença. PUBVET, Londrina, V. 2, N. 48, Art\#463, Dez1, 2008.

Vale ressaltar algumas condições físico-químicas de infecciosidade do papilomavírus. Em temperaturas entre $4{ }^{\circ} \mathrm{C}$ e $-70^{\circ} \mathrm{C}$, o vírus permanece ativo por 90 dias e 180 dias, respectivamente. O vírus também é conservado por longo tempo, quando mantido em glicerina a $50 \%$ ou quando liofilizado. Por outro lado, o vírus é inativado por 30 minutos a $60^{\circ} \mathrm{C}$ e em formalina a $10 \%$. O vírus é resistente aos solventes lipídicos, éter, grandes oscilações de pH (3,0 $7,5)$ e em temperaturas até $50^{\circ} \mathrm{C}$ (Murphy et al., 1999).

No Brasil, não há estudos conclusivos quanto ao risco humano. Mas segundo o manual de doenças de vida selvagem da Universidade do Canadá University of Northern British Columbia, a carne de um animal infectado é apropriada para o consumo humano desde que as lesões verrucosas não afetem a qualidade da mesma. Apesar da má aparência, os papilomas não oferecem risco à saúde do homem e estes provavelmente não se contaminam com as verrugas de mamíferos selvagens (Miller et al., 2003). Entretanto, na Grã-Bretanha, há estudos comprovados em que funcionários de abatedouros foram contaminados com o BPV (Stocco dos santos et al., 2003).

\section{Conclusão}

De acordo com os achados clínico-morfológicos deste presente estudo, os aspectos histopatológicos relativos à avaliação macro e microscópica das lesões estão compatíveis com o padrão histopatológico e clínico das lesões de PV. Este artigo alerta para o contato direto dos trabalhadores rurais e retireiros no manuseio do úbere e tetas de animais infectados pelo vírus do papiloma durante $o$ ato da ordenha. Igualmente, sinaliza para técnicos de laboratório e pesquisadores o risco em manipular material de vírus vivo.

Estudos comprovam que as classes menos favorecidas economicamente estão mais expostas aos riscos de infecções virais, como também outras doenças infecto-contagiosas. Nesse sentido, são oferecidos pelo Sistema Único de Saúde (SUS) exames ginecológicos para a deteç̧ão precoce de infecção ou 
Marins, R.S.Q.S. Risco de infecção cruzada: transmissão interespécies do papilomavírus humano e animal conferido pela expressão clínica da doença. PUBVET, Londrina, V. 2, N. 48, Art\#463, Dez1, 2008.

de uma possível neoplasia interepitelial cervical. Além disso, também é desenvolvido um trabalho de prevenção pelo Programa Nacional de Combate ao Câncer de Colo de Útero nas mulheres. Fazendo referência à doença como sexualmente transmissível, deve-se também dar maior enfoque à pesquisa do papilomavírus em lesões condilomatosas no homem, alertando seus parceiros sexuais para evitar possíveis formas de contágio, bem como a saúde do homem do campo, onde os recursos são mais precários e tardios.

Além disso, é necessário aprofundar os estudos no campo da genética com intuito de detectar seqüências de DNA do papilomavírus a partir de espécimes biológicos de lesões obtidas de biópsias cutâneas de trabalhadores do campo, como também pesquisar nas amostras de leite e da carne de bovinos que apresentam a papilomatose e em amostras de animais clinicamente livres da doença. Dessa forma, são imprescindíveis estudos adicionais voltados para responder se está realmente ocorrendo infecção cruzada entre diferentes hospedeiros e se a hipótese de uma possível zoonose deve ser descartar ou confirmada.

\section{Referências Bibliográficas}

ANTONSSON A., MC MILLAN, N.A.J. Papillomavirus in healthy skin of Australian animals. Journal of General Virology, 87, p.3195-3200, 2006.

CARVALHO, C., FREITAS, A.C., BRUNNER, O., GÓES, L.G.B., YAGUIU-CAVALCANTE, A., BEÇAK, W., STOCCO DOS SANTOS, R.C. Bovine papillomavirus type 2 in reproductive tract and gametes of slaughtered bovine females. Brazilian Journal Microbiology, 34 (1), p. 82-84, 2003.

CHAMBERS, G., ELLSMORE, V.A., O`BRIEN, P.M., REID, S.W.J., LOVE, S., CAMPO, M.S., NASIR, L. Association of bovine papillomavirus with the equine sarcoid. Journal of General Virology, 84, p. 1055-1062, 2003.

CHAN, S.Y., BERNARD, H.U., RATTERREE, M., BIRKEBAK, T.A., FARAS, A.J., OSTROW, R. Genomic diversity and evolution of papillomaviruses in Rhesus Monkeys. Journal of Virology, 71(7), p. 4938-4943, 1997. 
Marins, R.S.Q.S. Risco de infecção cruzada: transmissão interespécies do papilomavírus humano e animal conferido pela expressão clínica da doença. PUBVET, Londrina, V. 2, N. 48, Art\#463, Dez1, 2008.

INTERNATIONAL COMMITEE ON TAXONOMY OF VIRUSES - ICTV. ICTV approved Virus Orders, Families and Genera; <http://www.ncbi.nlm.nih.gov/ICTVdb/Ictv/index.htm>. Acesso em: 27 out..2008.

MAYR, A., GUERREIRO, M.G. Virologia Veterinária. 3.ed. Porto Alegre: editora sulina, 476 p, 1988.

MILLER, M.J.R., DAWSON, R.D., SCHWANTJE, H. Papillomavirus. In: Manual of common diseases and parasites of wildlife in Northern British Columbia, p.101-103,2003., <http://www.unbc.ca/nlul/wildlife_diseases_bc/papillomavirus.htm> Acesso em 28 de outubro de 2008.

MURPHY, F.A., GIBSS, P.J., HORZINEK, M.C., STUDDERT, M.J. Veterinary Virology, 3.ed. Academic Press, 629 p, 1999.

NASIR, L., GAULT, E., MORGAN, I.M., CHAMBERS, G., ELLSMORE, V., CAMPO, M.S. Identification and functional analysis of sequence variants in the long control region and the E2 open reading frame of bovine papillomavirus type 1 isolated from equine sarcoids. Virology, 364, p. $355-361,2007$.

NATIONAL CENTER FOR BIOTECHNOLOGY INFORMATION - NCBI. <http://www.ncbi.nlm.nih.gov/> Acesso em 28 de outubro de 2008.

OGAWA, T., TOMITA, Y., OKADA, M., SHINOZAKI, K., KUBONOYA, H., KAIHO, I., SHIRASAWA, $\mathrm{H}$. Broad-spectrum detection of papillomaviruses in bovine teat papillomas and healthy teat skin. Journal of General Virology, 85, p. 2191 - 2197, 2004.

REBHUN, W. C. Doenças das tetas e do úbere. In: Rebhun, E.C. (ed.) Doenças do Gado Leiteiro. São Paulo: Roca, p. 309 - 378, 2000.

RECTOR, A., BOSSART, G.D., GHIM, S-J., SUNDBERG, J.P., JENSON, A.B., RANST, M. V. Characterization of a novel close-to-root papillomavirus from a Florida Manatee by Using Multiply primed rolling-circle amplification: Trichechus manatus latirostris papillomavirus type1. Journal of Virology, 78 (22), p. 12698 - 12702, 2004.

RECTOR, A., DOORSLAER, K.V., BERTELSEN, M., BARKER, I.K., OLBERG, R.A., LEMEY, P., SUNDBERG, J.P., RANST, M.V. Isolation and cloning of the raccoon (Procyon lotor) papillomavirus type 1 by using degenerate papillomavirus-specific primers. Journal of General Virology, 86, p. $2029-2033$, 2005a.

RECTOR, A., MOSTMANS, S., DOORSLAER, K.V., McKNIGHT, C.A., MAES, R.K., WISE, A.G., KIUPEL, M., RANST, M.V. Genetic characterization of the first chiropteran papillomavirus, isolated from a basosquamous carcinoma in an Egyptian fruit bat: The Rousettus aegyptiacus papillomavirus type1. Veterinary Microbiology, 117, p. 267 - 275, 2006.

RECTOR, A., TACHEZY, R., DOORSLAER, K.V., Mac NAMARA, T., BURK, R.D., SUNDBERG, J.P., RANST, M.V. Isolation and cloning of a papillomavirus from a North American porcupine by using multiply primed rolling-circle amplification: the Erethizon dorsatum papillomavirus type 1. Virology, 331, p. $449-456,2005 b$.

REHTANZ, M., GHIM, S-J., RECTOR, A., RANST M.V., FAIR, P.A., BOSSART, G.D., JENSON, A.B. Isolation and characterization of the first American bottlenose dolphin papillomavirus: Tursiops truncates papillomavirus type 2. Journal of General Virology, 87, p. 3559 - 3565, 2006. 
Marins, R.S.Q.S. Risco de infecção cruzada: transmissão interespécies do papilomavírus humano e animal conferido pela expressão clínica da doença. PUBVET, Londrina, V. 2, N. 48, Art\#463, Dez1, 2008.

STEVENS, H., RECTOR, A., BERTELSEN, M.F., LEIFSSON, P.S., VAN RANST, M. Novel papillomavirus isolated from the oral mucosa of a polar bear does not cluster with other papillomaviruses of carnivores. Veterinary Microbiology, 129, p. 108-116, 2008.

STOCCO DOS SANTOS, R. C., BEÇAK, W., DINIZ, O., GARCIA, G. S., CARVALHO, C. Papilomavírus infecta $60 \%$ do rebanho bovino; 2003 <http://www.estadao.com.br> Acesso em 12 agosto. 2005.

SUNDBERG, J.P., MONTALI, R.J., BUSH, M., PHILLIPS, L.G., O`BRIEN, S.J., JENSON, A.B., BURK, R.D., VAN RANST, M. Papillomavirus-associated focal oral hyperplasia in wild and captive asian lions (Panthera leo persica). Journal of Zoo and Wildlife Medicine, 27, p.61-70, 1996.

TEIFKE, J.P., KIDNEY, B.A., LÖHR, C.V., YAGERS, J.A. Detection of papillomavirus-DNA in mesenchymal tumour cells and not in the hyperplastic epithelium of feline sarcoids. Veterinary Dermatology, 14, p. 47 - 56, 2003.

YAGUiU, A., CARVALHO, C., FREITAS, A.C., GÓES, L.G.B., DAGLI, M.L.Z., BIRGEL Jr, E.H., BEÇAK, W., STOCCO DOS SANTOS, R.C. Papillomatosis in cattle: in situ detection of bovine papilomavírus DNA sequences in reproductive tissues. Brazilian Journal Morphological Science, $23(3 / 4)$, p.129 -136, 2006.

WITTMANN, W. Infecções por papovavírus. In: Beer, J (ed.) Doenças Infecciosas em Animais Domésticos. São Paulo: Roca, p. 256 - 261, 1999.

WOODRUFF, R.A., BONDE, R.K., BONILLA, J.A., ROMERO, C.H. Molecular identification of a papilloma virus from cutaneous lesions of captive and free-ranging Florida Manatees. Journal of Wildlife Disease, 41, p.437-441, 2005. 